\title{
Symbiosis theory-directed green synthesis of silver nanoparticles and their application in infected wound healing
}

This article was published in the following Dove Press journal:

International Journal of Nanomedicine

10 June 2016

Number of times this article has been viewed

\author{
Lu Wen' \\ Pei Zeng' \\ Liping Zhang' \\ Wenli Huang' \\ Hui Wang ${ }^{2}$ \\ Gang Chen' \\ 'Department of Pharmaceutics, School \\ of Pharmacy, ${ }^{2} \mathrm{School}$ of Traditional \\ Chinese Medicine, Guangdong \\ Pharmaceutical University, Guangzhou, \\ People's Republic of China
}

Correspondence: Gang Chen

Department of Pharmaceutics, School of Pharmacy, Guangdong Pharmaceutical University, Guangzhou 510006, People's Republic of China

Tel +86203935 2117

Fax +86203935 2129

Emailcg753@126.com

\begin{abstract}
In this study, silver nanoparticles (AgNPs) were synthesized for the first time using an antibacterial endophytic fungus of Chinese medicinal herb Orchidantha chinensis, which has anti-inflammatory and antimicrobial activities. The AgNPs were analyzed by various characterization techniques to reveal their morphology, chemical composition, and stability. Also, the relationship between Chinese medicinal herbs, endophytic fungi, and the property of AgNPs was investigated for the first time. Interestingly, an experiment performed in this study revealed the proteins produced by the endophytic fungus to be capped on the nanoparticles, which led to an increase in the stability of spherical and polydispersed AgNPs with low aggregation for over 6 months. More importantly, further study demonstrated that the AgNPs possessed superior antibacterial activity and effectively promoted wound healing. Altogether, the biosynthesis of active AgNPs using the endophytic fungus from Chinese medicinal herb based on the symbiosis theory is simple, eco-friendly, and promising.
\end{abstract}

Keywords: silver nanoparticles, Orchidantha chinensis, endophytic fungi, symbiosis theory, wound healing

\section{Introduction}

In recent years, nanoparticles have been increasingly studied in the field of biomedical sciences. A lot of research is available on the different kinds of nanoparticle vectors utilized in the field of biomedical applications, such as polymers, lipids, peptides, and small molecules. ${ }^{1-4}$ Silver nanoparticles (AgNPs), which are among the most widely used nanomaterials owing to their unique optical, electrical, catalytic, and antimicrobial properties, have been applied in various fields such as biomedicine, drug delivery, and agriculture. ${ }^{5,6}$ To date, green approaches for AgNPs synthesis from microorganisms are potential candidates for the development of manufacturing techniques that are more eco-friendly than the physical and chemical methods often used nowadays. ${ }^{7,8}$ Microorganisms interact with silver ions and reduce them into AgNPs, which have raised among researchers a great interest to explore the biological systems. Fungi secrete enzyme extracellularly, which has an additional advantage in the downstream processing and handling of biomass. ${ }^{9}$ Moreover, fungi are excellent secretors of proteins compared to other microorganisms, resulting in higher yield of nanoparticles. $^{10}$

According to the concept and connotation of the symbiosis theory, endophytic fungi are the chemical synthesizers that reside in tissues of the host plant and are known to produce the same or similar metabolites as the host, which often display the traits 
of proven efficacy and low toxicity. ${ }^{11,12}$ However, only very few of them have been cultivated and screened for synthesizing the corresponding active nanomaterials. We therefore initiated a research program focusing exclusively on the relationship of the active endophytic fungi isolated from Chinese medicinal herb with the biosynthetic AgNPs with respect to physical property and activity.

Orchidantha chinensis is a Chinese medicinal herb, which can clear away heat and purge fire, moisten the lung, and relieve cough according to the theory of traditional Chinese medicine. It has also been commonly applied to anti-inflammatory and antimicrobial infection in clinic treatment. ${ }^{13}$ However, O. chinensis has been collected and listed in the "Chinese Directory of Endangered Plant" because the raw resource is endangered. ${ }^{14}$ Hence, it is necessary to exploit the endophytic fungal resources that have homologous relationships with $O$. chinensis for their application in nanomaterials biosynthesis.

In the present study, we report for the first time the biosynthesis of AgNPs using an antibacterial endophytic fungus (Penicillium spinulosum OC-11) from $O$. chinensis and their application in infected wound healing. In this study, a green synthesis of AgNPs was carried out for the first time using the cell filtrate of $P$. spinulosum OC-11, which acted as a reducing and capping agent for the reduction of silver ions. The biosynthetic AgNPs were characterized by UV-vis spectroscopy, transmission electron microscopy (TEM), dynamic light scattering (DLS), X-ray diffraction (XRD), and Fourier transform infrared spectroscopy (FTIR). The stability of AgNPs colloidal solution was investigated by recording UV-vis absorption spectra and measuring particle size distribution. Furthermore, the antibacterial activities of AgNPs were detected with the disc diffusion assay and broth dilution method. In vivo wound-healing activity was studied using an infected wound model, and wound closure, bacterial count, as well as levels of proinflammatory cytokines, hydroxyproline, and total protein were evaluated.

\section{Materials and methods Materials}

The endophytic fungus OC-11 was isolated from $O$. chinensis in the South China Botanical Garden and identified as P. spinulosum by Beijing Dingguo Changsheng Biotechnology Co., Ltd. (Beijing, People's Republic of China), which showed excellent antibacterial activity against pathogenic microorganisms (Staphylococcus aureus, Pseudomonas aeruginosa, and Escherichia coli). The fungus was maintained on potato dextrose agar slants containing $300 \mathrm{~g} / \mathrm{L}$ potatoes, $20 \mathrm{~g} / \mathrm{L}$ dextrose, $0.1 \mathrm{~g} / \mathrm{L}$ chloramphenicol, and $15 \mathrm{~g} / \mathrm{L}$ agar at $4^{\circ} \mathrm{C}$. All chemicals used in this study were of analytical grade. Silver nitrate $\left(\mathrm{AgNO}_{3}\right)$ was purchased from Jinzhujiang Chemistry Co., Ltd. (Guangzhou, People's Republic of China). Povidone-iodine solution $(10 \mathrm{mg} / \mathrm{mL})$ was provided by Jiangmen Hengjian Pharmaceutical Co., Ltd. (Jiangmen, People's Republic of China).

\section{Biosynthesis of AgNPs}

The strain $P$. spinulosum OC-11 was inoculated in peptone yeast glucose broth containing $1 \mathrm{~g} / \mathrm{L}$ yeast extract, $2 \mathrm{~g} / \mathrm{L}$ sea salt, $2 \mathrm{~g} / \mathrm{L}$ peptone, and $5 \mathrm{~g} / \mathrm{L}$ glucose at $28^{\circ} \mathrm{C}$ in a rotary shaker (TCYQ; Taicang Laboratory Equipment Factory, Taicang, People's Republic of China) at $120 \mathrm{rpm}$ for 72 hours. After fermentation, the biomass was separated by filtration and then washed with distilled water to remove any media components. Approximately $10 \mathrm{~g}$ fungal biomass was resuspended in $100 \mathrm{~mL}$ distilled water and incubated for 24 hours at $28^{\circ} \mathrm{C}$, and the cell filtrate was obtained through Whatman No 1 filter paper. $\mathrm{AgNO}_{3}$ solution $(10 \mathrm{mM})$ was added to the cell filtrate in a ratio of 1:9, and incubated at room temperature in dark for 72 hours. Simultaneously, the control (only the cell filtrate without $\mathrm{AgNO}_{3}$ ) was also checked for comparison. AgNPs were washed thoroughly, and then collected by ultracentrifugation at 20,000 rpm for 90 minutes (Optima L-100 XP; Beckman Coulter, Brea, CA, USA) and then freeze-dried for further study.

\section{Characterization and stability evaluation}

Bioreduction of $\mathrm{Ag}^{+}$ions was characterized by UV-vis spectrophotometer (Shimadzu UV2550; Kyoto, Japan) over a wavelength range of 300-700 $\mathrm{nm}$ for 72 hours after incubation. The cell filtrate was used as a blank. Size distribution and zeta potential were measured by DLS performed on a Delsa Nano C of Beckman Coulter. Additionally, morphology was visualized by Hitachi-7650 TEM instrument operated at an accelerating voltage of $80 \mathrm{kV}$, in which the sample was prepared by dripping AgNPs colloidal solution onto the carbon-coated copper grid. XRD study was used to evaluate the crystal structure of the nanocrystals using Smart 1000 CCD X-ray diffractometer (Bruker Madison, WI, USA) with $\mathrm{Cu} \mathrm{K} \alpha$ radians at $2 \theta$ angles ranging from $20^{\circ}$ to $80^{\circ}$. The FTIR spectra of both the cell filtrate and AgNPs were measured using Shimadzu Spectrum-100 FTIR spectrometer in the range of $4,000-450 \mathrm{~cm}^{-1}$ to detect the possible functional groups involved in the formation of AgNPs. The stability of the synthesized AgNPs was further studied by recording UV-vis absorption spectra and measuring particle 
size distribution of the same colloidal solution preserved at room temperature in dark for 1, 2, 3, and 6 months.

\section{Antibacterial assays}

S. aureus ATCC 25923 and P. aeruginosa ATCC 27853 purchased from Guangdong Huankai Microbial Sci and Tech. Co., Ltd. (Guangzhou, People's Republic of China) and E. coli ATCC 25922 obtained from Guangdong Center for Clinical Laboratory (Guangzhou, People's Republic of China) were used to determine the antibacterial activities of AgNPs. Bacterial strains were maintained at $4^{\circ} \mathrm{C}$ in Luria-Bertani (LB) agar slants (containing $10 \mathrm{~g} / \mathrm{L}$ peptone, $5 \mathrm{~g} / \mathrm{L}$ yeast extract, $5 \mathrm{~g} / \mathrm{L}$ sodium chloride, $1 \mathrm{~g} / \mathrm{L}$ dextrose, and $15 \mathrm{~g} / \mathrm{L}$ agar).

In vitro antibacterial activities of AgNPs were evaluated against the three pathogenic bacteria by the disc diffusion assay and broth dilution method. The bacterial strains were grown overnight on LB agar plates at $37^{\circ} \mathrm{C}$. Overnight cultures of bacterial suspensions were adjusted to $1.0 \times 10^{6} \mathrm{CFU} / \mathrm{mL}$ and then swabbed uniformly onto the agar surface by a sterile cotton swab. Each sterile filter disc (diameter: $6 \mathrm{~mm}$ ) was placed on the surface of the prepared plates, impregnated with $15 \mu \mathrm{L}$ of test samples (three for AgNPs and one for cell filtrate), and incubated at $37^{\circ} \mathrm{C}$ for 24 hours. The inhibition zones were measured in millimeters. All tests were done in triplicate. The minimum inhibitory concentrations (MICs) were determined for all bacterial strains used in this study by the broth dilution method. Briefly, twofold dilutions of the AgNPs colloidal solution $(1.8,3.5,7.0,14.1,28.1,56.3,112.5$, and $225 \mu \mathrm{g} /$ $\mathrm{mL}$ ) were added to the test tubes containing an equal volume of bacterial suspension $\left(2.0 \times 10^{6} \mathrm{CFU} / \mathrm{mL}\right)$ and incubated for 24 hours at $37^{\circ} \mathrm{C}$. MIC was defined as the lowest sample concentration that inhibited visible growth in the tubes.

\section{In vivo wound-healing study}

Sprague Dawley rats weighing 180-220 g were purchased from the Laboratory Animal Center of Guangzhou University of Chinese Medicine. Animals were housed in a room with controlled temperature $\left(25^{\circ} \mathrm{C}\right)$ and relative humidity $(50 \% \pm 5 \%)$ for 12 -hour light/dark cycles with free access to water and food during the studies. All the protocols were approved by the Animal Ethical Committee on Care and Use of Experimental Animals at Guangdong Pharmaceutical University (Guangzhou, People's Republic of China). Twelve hours before experiments, the rats were fasted but had free access to water.

The rats were randomly divided into three groups: the normal saline group, the povidone-iodine group, and the AgNPs group. After anesthesia, the dorsal fur of the animal was shaved, and two full-thickness skin wounds of $1.8 \mathrm{~cm}$ diameter were created using a surgical blade and scissors for infected wound model. For the infected wound model, $1 \mathrm{~mL}$ of bacterial suspension (mixture of $S$. aureus and $P$. aeruginosa at equal volume and concentration, $1.0 \times 10^{9} \mathrm{CFU} / \mathrm{mL}$ ) was added to each wound bed immediately after wound surgery and left open for infection for 24 hours. A dressing coated with AgNPs solution $\left(0.04 \mathrm{mg} / \mathrm{cm}^{2}\right)$ was topically applied to the wound bed in the AgNPs group. ${ }^{15}$ In the povidoneiodine group, the rats were treated by topical application of povidone-iodine solution. Wound bed in the control group was covered with a normal saline-coated dressing. The wound dressings were changed daily until sacrifice or wound healing. The rats were monitored daily, and the wounds were photographed $0,3,7,14$, and 21 days after treatment. The wound-healing rate was expressed as percentage of wound contraction rate (WCR\%) and calculated using Equation 1:

$$
\mathrm{WCR} \%=\frac{\left(A_{0}-A_{t}\right)}{A_{0}} \times 100
$$

where $A_{0}$ is the initial wound area and $A_{t}$ is wound area at time $t$.

The wound tissues were harvested and cut into halves, and one half was homogenized using a FJ200-SH digital high-speed disperser homogenizer (Shanghai Specimen and Control Factory, Shanghai, People's Republic of China) and suspended in sterile PBS. Samples from the tissue homogenates were serially diluted and plated on LB agar plates to count $S$. aureus and $P$. aeruginosa. The other half of each tissue sample was used to determine the concentrations of proinflammatory cytokines (tumor necrosis factor alpha $[$ TNF- $\alpha$ ], interleukin [IL]-1 $\beta$, and IL-6) by using enzymelinked immuno sorbent assay kit (Tianjing Boruikang Biant Technology Co., Ltd., Tianjing, People's Republic of China) according to the manufacturer's instructions. Total protein of the tissue homogenates was determined by using total protein assay kit with the standard bicinchoninic acid method (Nanjing Jiancheng Bioengineering Institute, Nanjing, People's Republic of China). For histological studies, cross-sectional skin samples collected on the third, seventh, 14th, and 21 st days were stained with hematoxylin and eosin and examined under a light microscope (Olympus BX51; Tokyo, Japan).

\section{Statistical analysis}

All the results were expressed as mean \pm standard deviation. Statistical significance was determined by using one-way 
analysis of variance performed using New Drug Statistical Treatment (NDST version 2002 for Windows).

\section{Results and discussion \\ Characterization of AgNPs}

UV-vis spectroscopy analysis

The fungal cell filtrate changed from colorless to yellow after being mixed with $\mathrm{AgNO}_{3}$ for 72 hours, suggesting that AgNPs were successfully synthesized. Due to the excitation of surface plasmon vibrations with AgNPs, the biosynthetic AgNPs were certified by a characteristic surface plasmon resonance (SPR) peak at $420 \mathrm{~nm}$ in UV-vis spectrum. ${ }^{16} \mathrm{It}$ is well known that the optical absorption spectrum of AgNPs, which is dominated by SPRs, shifts to longer wavelengths with increasing particle size. ${ }^{17}$

\section{TEM and DLS analyses}

TEM micrograph showed that the majority of AgNPs was spherical or nearly spherical in shape and well distributed, with a diameter of $\sim 25 \mathrm{~nm}$ (Figure 1A). DLS analysis showed the size distribution of particles with an average hydrodynamic size of $46.1 \mathrm{~nm}$ and a low polydispersity index of 0.131, indicating good uniformity of AgNPs in the colloidal solution (Figure 1B). The zeta potential was $-24.6 \mathrm{mV}$. The negatively charged surfaces of AgNPs were coordinated with anionic coating agents, representing sufficient mutual repulsion to ensure the colloid stability. ${ }^{18}$ Notably, the average particle size estimated by TEM measurements was smaller than that estimated by the particle size analyzer because the particle size was increased significantly by the hydrated capping agents (probably proteins) and solvation effects. ${ }^{19}$

\section{XRD analysis}

The crystalline nature of the AgNPs was elucidated using XRD analysis. In the XRD spectra of AgNPs, the diffraction peaks at $2 \theta=32.16^{\circ}, 38.03^{\circ}, 46.15^{\circ}, 64.51^{\circ}$, and $76.70^{\circ}$ corresponded to (101), (111), (200), (220), and (311) planes of the face-centered cubic crystal structure, respectively
A
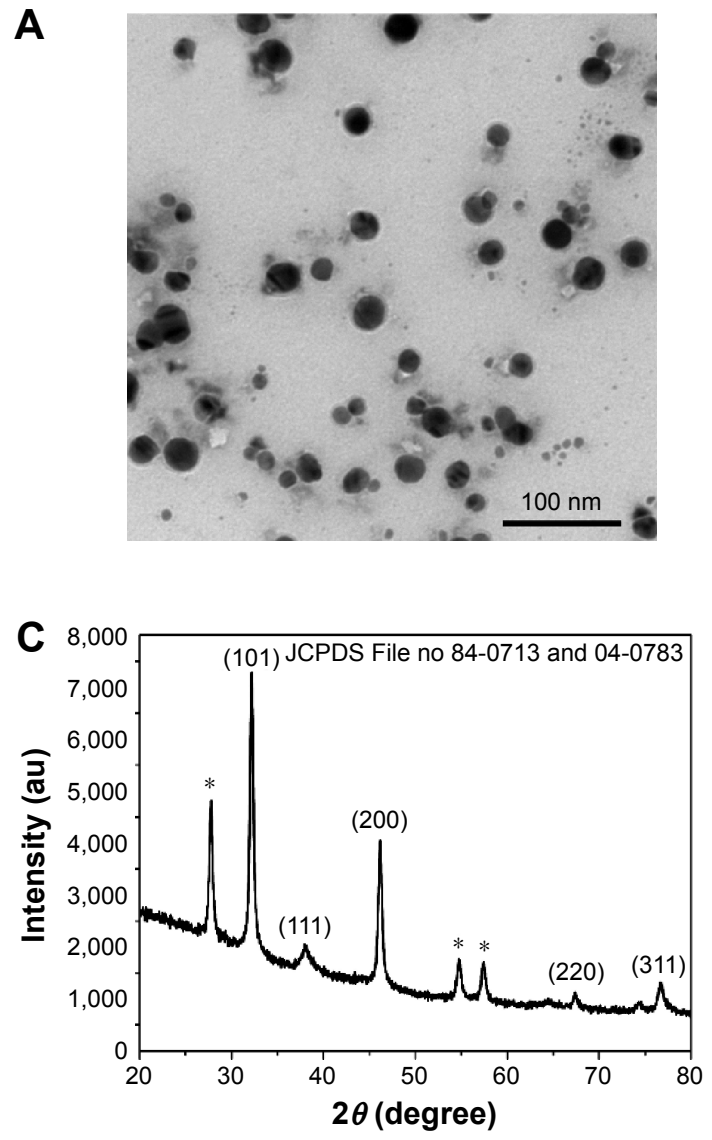

B
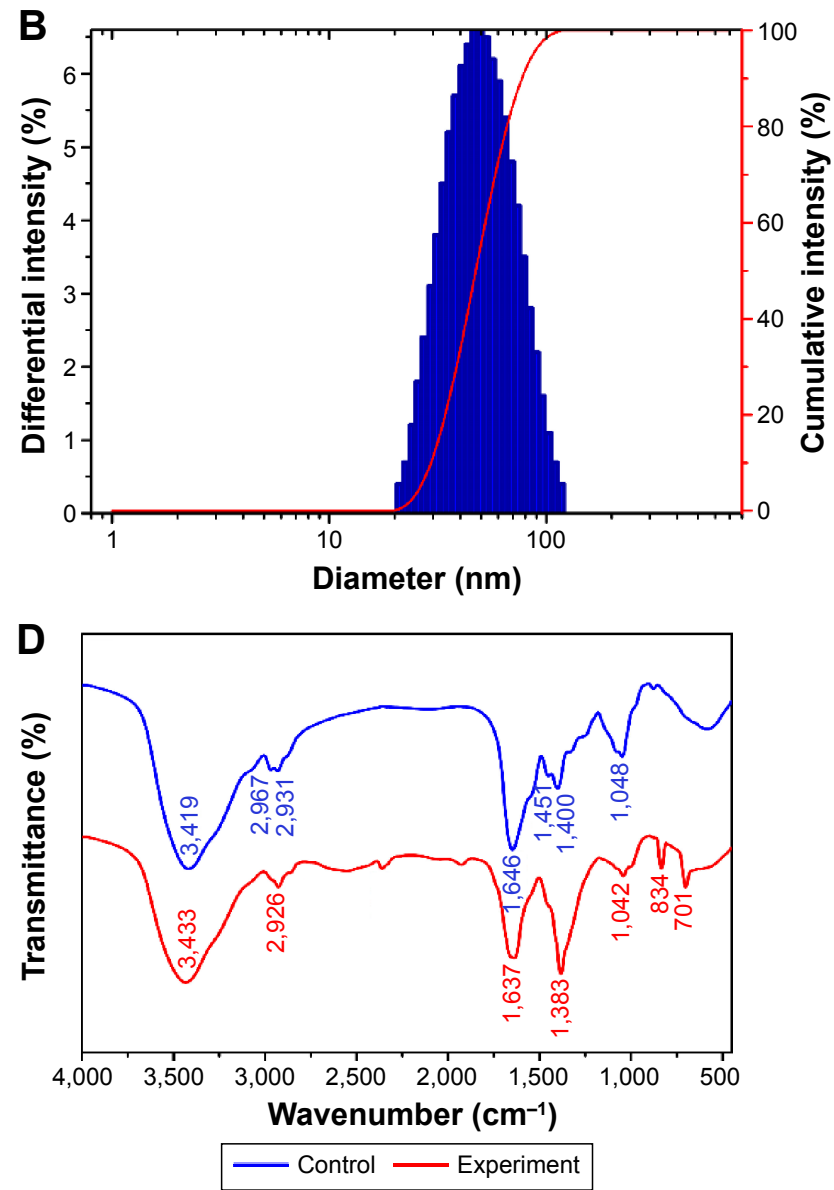

Figure I Characterization of AgNPs.

Notes: (A) TEM micrograph. (B) Particle size distribution. (C) XRD pattern (*is unidentified peak). (D) FTIR spectra.

Abbreviations: AgNPs, silver nanoparticles; TEM, transmission electron microscopy; XRD, X-ray diffraction; FTIR, Fourier transform infrared spectroscopy; au, arbitrary units. 
(Figure 1C). The XRD pattern clearly demonstrated that the synthesized AgNPs were crystalline in nature (JCPDS File no 84-0713 and 04-0783), being consistent with earlier reports. ${ }^{20,21}$ Unidentified peaks $\left(27.74^{\circ}, 54.73^{\circ}, 57.40^{\circ}\right)$ were also observed, which could be attributed to the biomass residue and capping agents used for AgNP formation. ${ }^{22}$

\section{FTIR analysis}

The FTIR spectra showed distinct absorption peaks at 3,419, $2,967,2,931,1,646,1,451,1,400$, and $1,048 \mathrm{~cm}^{-1}$ for the cell filtrate of $P$. spinulosum $\mathrm{OC}-11$ and major peaks at 3,433, 2,926, 1,637, 1,383, 1,042, 834, and $701 \mathrm{~cm}^{-1}$ for AgNPs (Figure 1D). In comparison with the FTIR spectrum of control, the major peaks at $\sim 3,433,1,637$, and $1,383 \mathrm{~cm}^{-1}$ in the experimental demonstrated the presence of amides on the surface of the AgNPs. The biomolecules on the AgNPs might have been the peptides and proteins present in the cell-free extract. ${ }^{23}$ The amide linkages between amino acid residues in proteins gave rise to well-known signatures in the infrared region of the electromagnetic spectrum. ${ }^{7}$ FTIR spectrum of the AgNPs revealed a strong broad absorption peak at 3,433 $\mathrm{cm}^{-1}$, which is characteristic of $\mathrm{O}-\mathrm{H}$ stretching vibration of the polysaccharide and $\mathrm{N}-\mathrm{H}$ stretching vibration of protein. ${ }^{24}$ A peak at $2,926 \mathrm{~cm}^{-1}$ was assigned to $\mathrm{C}-\mathrm{H}$ stretching vibration of the polysaccharide. The absorption peak at $1,637 \mathrm{~cm}^{-1}$ was assigned to the absorbance of $\mathrm{C}=\mathrm{O}$ stretching vibration and $\mathrm{N}-\mathrm{H}$ bending vibration of the amide I band, ${ }^{25}$ and the band at $1,637 \mathrm{~cm}^{-1}$ is also characteristic of $\beta$-sheet structure of the protein. ${ }^{26}$ The band observed at $\sim 1,383 \mathrm{~cm}^{-1}$ was assigned to the $-\mathrm{H}-\mathrm{N}-\mathrm{C}=\mathrm{O}$ stretching vibration of the amide III band of the protein, which is the cis configuration. ${ }^{27}$ The specific band at $1,042 \mathrm{~cm}^{-1}$ was due to the pyranose ring. ${ }^{28,29}$ The wave number at $834 \mathrm{~cm}^{-1}$ represented the fingerprint region for $\alpha$-glycosidic bond carbohydrate. ${ }^{29}$ The peak at $701 \mathrm{~cm}^{-1}$ was attributed to $\mathrm{N}-\mathrm{H}$ bending vibration. From these observations, it was thought that it was likely a glycoprotein containing polysaccharide with $\alpha$-glycosidic bond and protein with $\beta$-sheet which capped on the AgNPs. Similarly, several studies have reported that bonds such as $\mathrm{C}-\mathrm{N}$ and $-\mathrm{C}-\mathrm{O}-\mathrm{C}-$ or functional groups such as amide are derived from heterocyclic compounds like amino acids, the building blocks of protein, which were present in the cell-free extract of the endophytic fungus and acted as the capping ligands and adsorbed strongly to the AgNPs. ${ }^{30-33}$

\section{Stability studies}

After a continued test at room temperature, it was found that AgNPs colloidal solution remained clear, transparent, and spherical, and polydispersed for 6 months (Figure 2A). SPR change was not shown in the UV-vis spectrum of AgNPs, which retained a typical peak at $420 \mathrm{~nm}$ (Figure 2B). Furthermore, DLS measurements revealed that the average particle size barely changed ( $45-51 \mathrm{~nm})$ after storage for $1,2,3$, and 6 months (Figure 2C). Combined with the results of FTIR analysis, it was indicated that the proteins adsorbed strongly on the metals, and the proteins could have also formed a layer along with other bio-organic molecules. It was also shown in the "TEM and DLS analysis" section that the polydispersed spherical AgNPs were surrounded by an organic layer which should have been the surface-bound proteins. All of these experimental results described demonstrated that the proteins produced by the fungus OC-11 capped on the AgNPs, secured the nanoparticles with low aggregation, and subsequently added advantage for the stabilization of AgNPs. And to our knowledge, AgNPs that were synthesized were more stable than the AgNPs that were biosynthesized by other Penicillium spp., and the AgNPs colloidal solution remained stable for up to 6 months at room temperature without obvious change. ${ }^{18,34}$

\section{Antibacterial assays}

The strain $P$. spinulosum OC-11 exhibited strong inhibitory effects against $S$. aureus ATCC 25923, P. aeruginosa ATCC 27853, and E. coli ATCC 25922 with inhibition zones of $28.5,30$, and $18.5 \mathrm{~mm}$, respectively (Table 1 ). The preliminary antibacterial activity of AgNPs was detected using the disc diffusion assay. The maximum zones of inhibition of S. aureus ATCC 25923 and P. aeruginosa ATCC 27853 were both $15 \mathrm{~mm}$, whereas that of E. coli ATCC 25922 was $10 \mathrm{~mm}$. To confirm the antibacterial effect, MIC of AgNPs was calculated using the broth dilution method. P. aeruginosa ATCC 27853 appeared more sensitive to AgNPs, with an MIC of $14 \mu \mathrm{g} / \mathrm{mL}$ (Table 1). The inhibitory effect of AgNPs on various pathogenic bacteria was corresponding to that of the endophytic fungus. Thus, we speculated that the special proteins capped on the AgNPs influenced the antibacterial activity of the nanoparticles.

\section{In vivo wound-healing study}

From the series of experiments described, it can be concluded that the special proteins metabolized by the antibacterial endophytic fungus improved the inhibitory effect and raised the identification to $S$. aureus, $P$. aeruginosa, and $E$. coli of the AgNPs. Moreover, a whole in vivo wound-healing study was carried out to verify the relationship between Chinese medicinal herb, endophytic fungi, and the property of AgNPs using an infected wound model. 

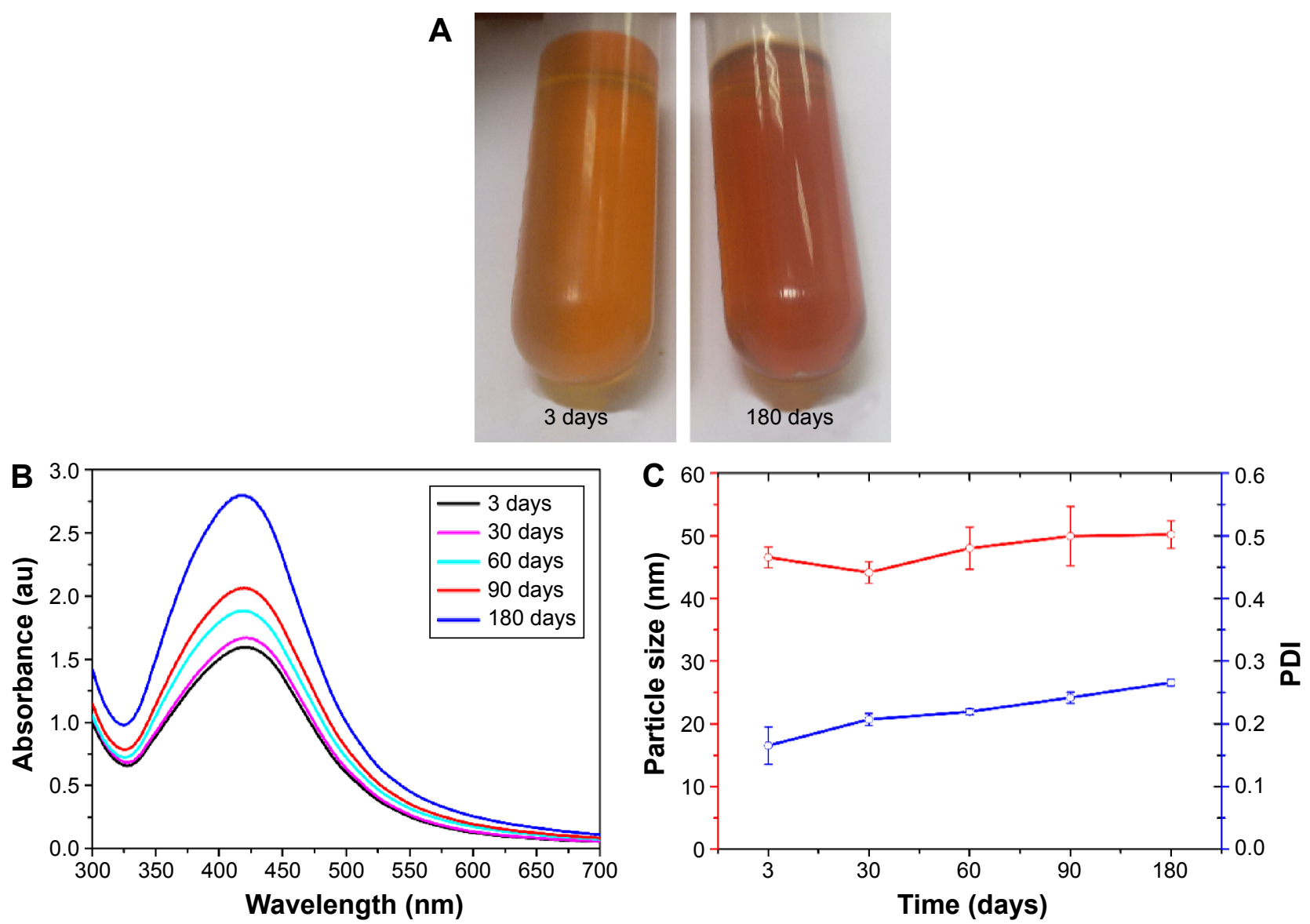

Figure 2 Stability studies of AgNPs.

Notes: (A) Change in the color of the broth confirming formation of AgNPs; (B) Ultraviolet-Visible spectra of AgNPs as the time of incubation increases. (C) Average particle size and PDI.

Abbreviations: AgNPs, silver nanoparticles; PDI, polydispersity index.

\section{Wound closure}

Generally, each wound was photographed 3, 7, 14, and 21 days after treatment (Figure 3). All the tested animals formed scabs at the wound site, which lasted for several days and left residual lesions on the skin tissue after they fell. Wound closure was clearly observed in the AgNPs group after 7 days, which corresponded to the result of WCR \% measurement (Figure 3). The AgNPs group showed an improvement in the overall appearance of the wound, with reduced inflammation indicated by relieved redness and minimal scarring on day 14. In contrast, in the control group, either a portion of the scab was retained or the scab had shed but exhibited a scarred, inflamed wound. WCR\% of the AgNPs-treated group significantly exceeded that of the control group $(P<0.05$ on days $3,7,14$, and 21$)$ and was up to $95.54 \% \pm 2.70 \%$ on day 21 , suggesting an almost complete wound closure. These observations indicated that wound healing was accelerated by AgNPs.

\section{Measurements of bacterial counts}

Bacterial infection is one of the most serious complications impairing wound healing and tissue regeneration, and pathogens in the wound fluid produce toxins and enzymes that prolong inflammatory responses and hence delay

Table I Antibacterial activities of AgNPs and Penicillium spinulosum OC-I I against three pathogenic bacterial strains

\begin{tabular}{llll}
\hline Bacteria & Inhibition zones $(\mathbf{m m})$ & MIC $(\mu \mathrm{g} / \mathbf{m L})$ of AgNPs \\
\cline { 2 - 4 } & AgNPs & P. spinulosum OC-II & \\
\hline Staphylococcus aureus & 15 & 28.5 & 28 \\
Pseudomonas aeruginosa & 15 & 30 & 14 \\
Escherichia coli & 10 & 18.5 & 28 \\
\hline
\end{tabular}

Abbreviations: AgNPs, silver nanoparticles; MIC, minimum inhibitory concentration. 


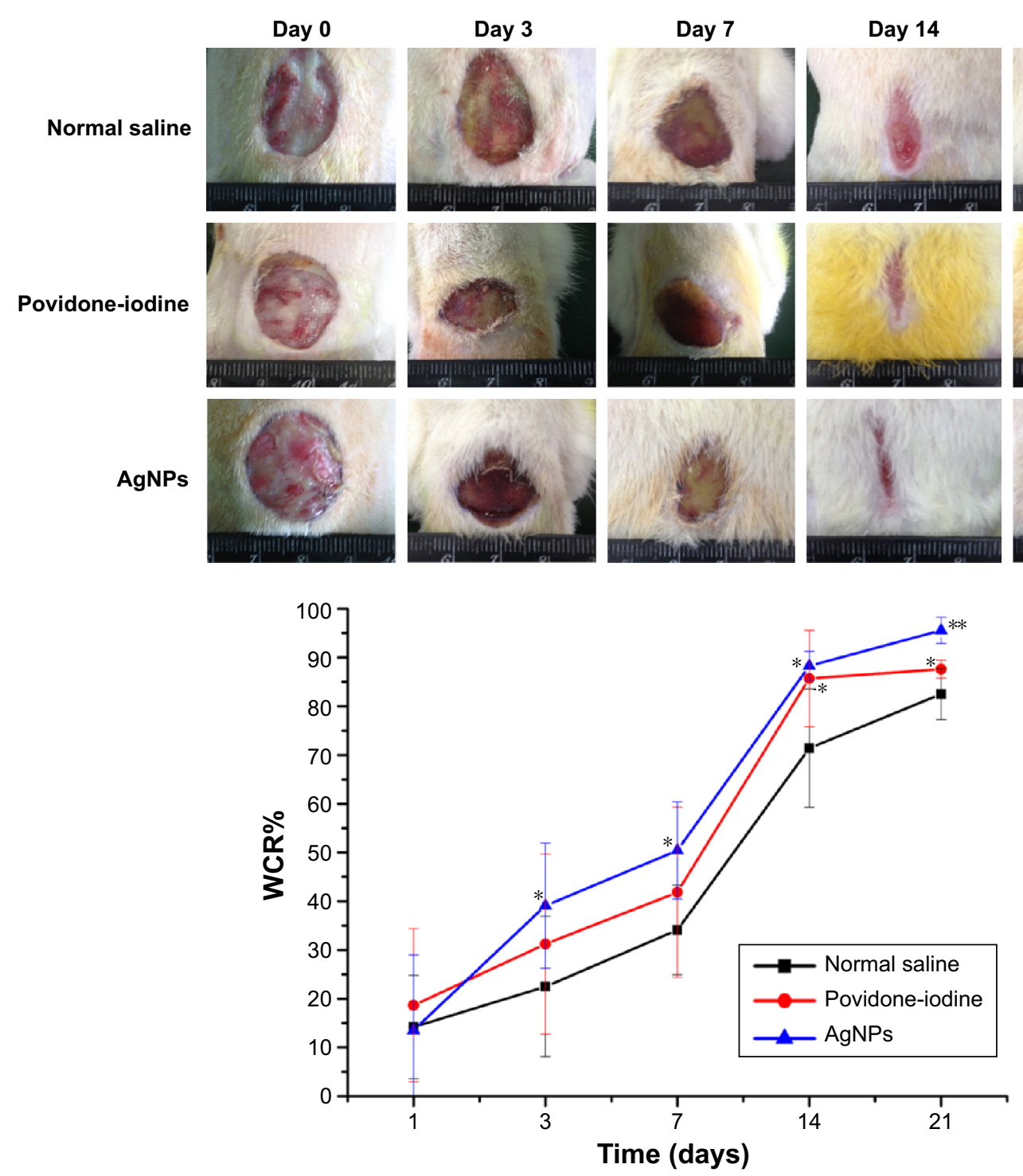

Figure 3 Appearance of wound and WCR\% of rats for up to 21 days.

Notes: Values are mean \pm SD for $n=6-8$. Statistical differences were found between samples labeled with $* P<0.05$ and $* * P<0.01$ compared to the control and normal saline. Abbreviations: WCR\%, percentage of wound contraction rate; SD, standard deviation; AgNPs, silver nanoparticles.

wound recovery. ${ }^{35}$ P. aeruginosa and $S$. aureus are the most common bacteria responsible for wound infection. ${ }^{36}$ To study the effects of AgNPs-inhibited bacterial growth on wound infection, the bacterial count of wound tissue was examined (Figure 4). On the first day, bacterial counts on the wound tissues of all groups, except that of S. aureus in the AgNPs group, did not differ significantly. On day 3 , though bacterial counts increased in all the infected wounds, the numbers of $S$. aureus and $P$. aeruginosa in both AgNPs and povidoneiodine groups were still significantly lower than those of control wounds. Furthermore, bacterial counts plummeted from day 3 to day 7 in all groups and then decreased slowly, probably because early inflammatory effects helped abolish the bacterial infection. Both AgNPs and povidone-iodine groups had significantly lower bacterial counts of $S$. aureus and $P$. aeruginosa than those of the control group $(P<0.05)$. Accordingly, both AgNPs and povidone-iodine effectively inhibited bacterial growth on the wound tissue and provided a better local environment for accelerating the woundhealing process.

\section{Levels of proinflammatory cytokines}

All stages of the wound-healing process are regulated by different growth factors, chemokines, and cytokines. Particularly, cytokines influence different processes at the wound site such as granulation tissue synthesis, fibroblast proliferation, and formation of collagen. Proinflammatory cytokines such as TNF- $\alpha$, IL-1 $\beta$, and IL-6 play major 

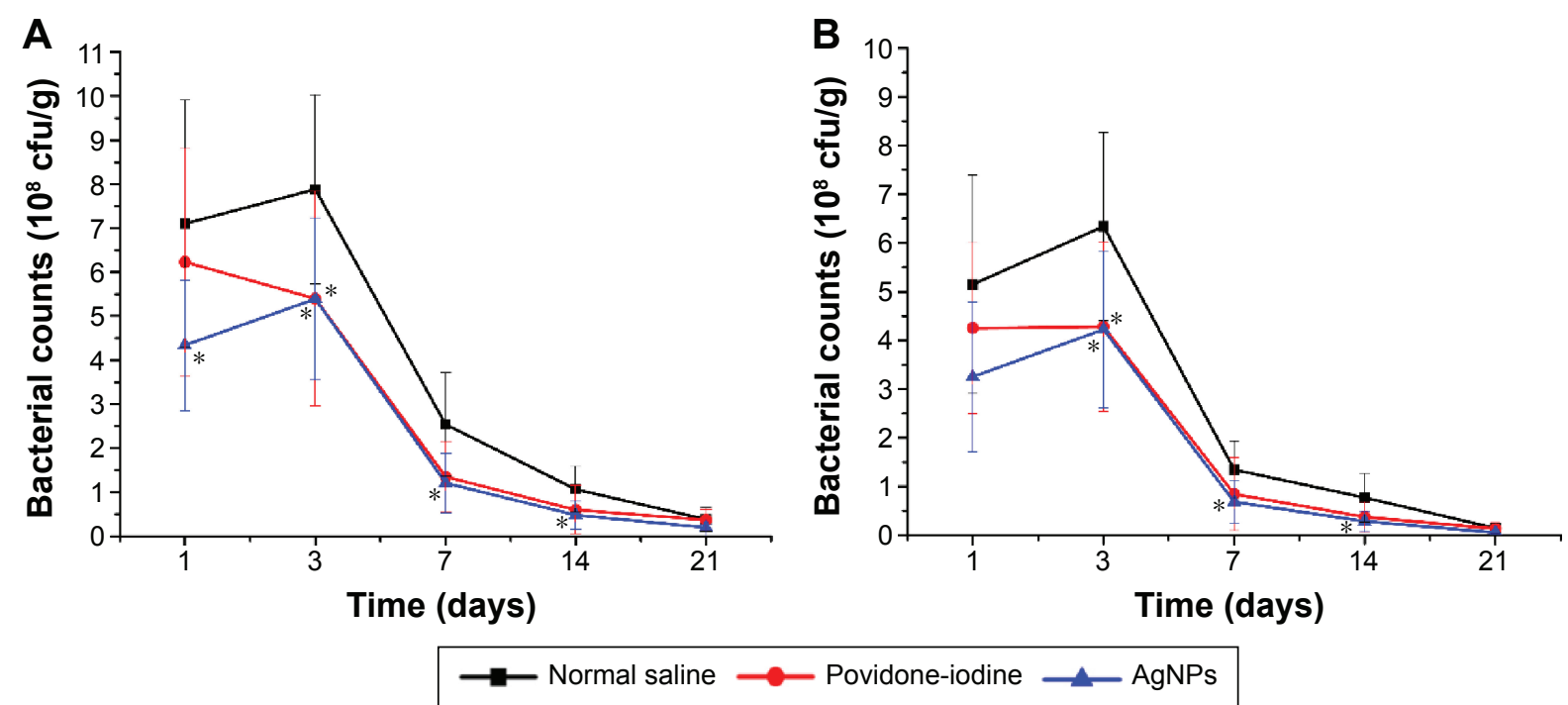

Figure 4 Bacterial counts of (A) Staphylococcus aureus and (B) Pseudomonas aeruginosa in wound tissue.

Notes: Values are mean \pm SD for $n=6-8$. Statistical differences were found between samples labeled with $* P<0.05$ compared to the control, normal saline. Abbreviations: SD, standard deviation; AgNPs, silver nanoparticles; cfu, colony-forming units.

roles in wound healing. ${ }^{37}$ Herein, the levels of TNF- $\alpha$, IL-1 $\beta$, and IL-6 in wound tissue homogenates were measured 21 days after treatment. Wounds treated with either AgNPs or povidone-iodine had significantly lower levels of TNF- $\alpha$ and IL-6 throughout the healing process $(P<0.05)$ than those of the control group (Figure 5). In this study, the concentrations of IL-1 $\beta$ in AgNPs and povidone-iodine groups also increased from the early phase of wound and reached maxima on day 3 , while that of the control group peaked on day 7 and remained higher. Proinflammatory cytokines can protect against potential invasion of a variety of microorganisms, while persistent inflammatory response after wounding through excessive production of TNF- $\alpha$, IL- $1 \beta$, and IL-6 also delays healing and increases complications. Therefore, downregulation of proinflammatory cytokines TNF- $\alpha$, IL- $1 \beta$, and IL-6 levels by AgNPs treatment can alleviate wound inflammation and enhance wound closure.

\section{Measurements of hydroxyproline and total protein contents}

The proliferative process of wound healing is typified by increased collagen content in the extracellular matrix. As hydroxyproline is a major constituent of and found almost exclusively in collagen, we measured hydroxyproline content in the wound tissue. Figure 5 shows that the hydroxyproline levels of both AgNPs and povidone-iodine groups exceeded that of the control group ( $P<0.05$ on 7 and 14 days). Similarly, protein content of the AgNPs group was significantly higher on days 3 and 7 , which then reduced in the later phase of wound healing. The increase in the total protein content in the initial phase of healing in the AgNPs-treated wounds indicated cellular hyperplasia as well as formation and deposition of matrix proteins in granulation tissues augmenting collagen generation. Given that the levels of hydroxyproline and protein rose in the AgNPs group, wound healed faster than that of the control.

\section{Histological analysis}

To better understand the influence of AgNPs on wound healing, the infected wounds of all groups were subjected to histological examination. As shown in Figure 6, there were massive inflammatory cells at the wound site in the control group on day 3 due to infection without perfect repair. Although neutrophils flowed into the wounds of all experimental groups initially, we found significantly fewer neutrophils in the AgNPs group on day 7. This suggested a reduced inflammatory response at the wound site. Notably, AgNPs better reconstructed wound than povidone-iodine did 7 days after treatment, as shown by the extent of the nascent granulation layer and the regeneration and development of hair follicles in the wound. On day 14, newly synthesized fibrous tissues and sparse inflammatory cells in the dermis and subcutis were covered by completely reepithelialized epidermis in the AgNPs group. After 21 days, the skin morphology of the AgNPs group was quite normal, and collagen in new dermis tissues was dense. These results further confirmed that AgNPs induced faster formation of granulation tissues and collagen, with milder edema and inflammatory response than those of the control group, indicating the acceleration of wound healing. 

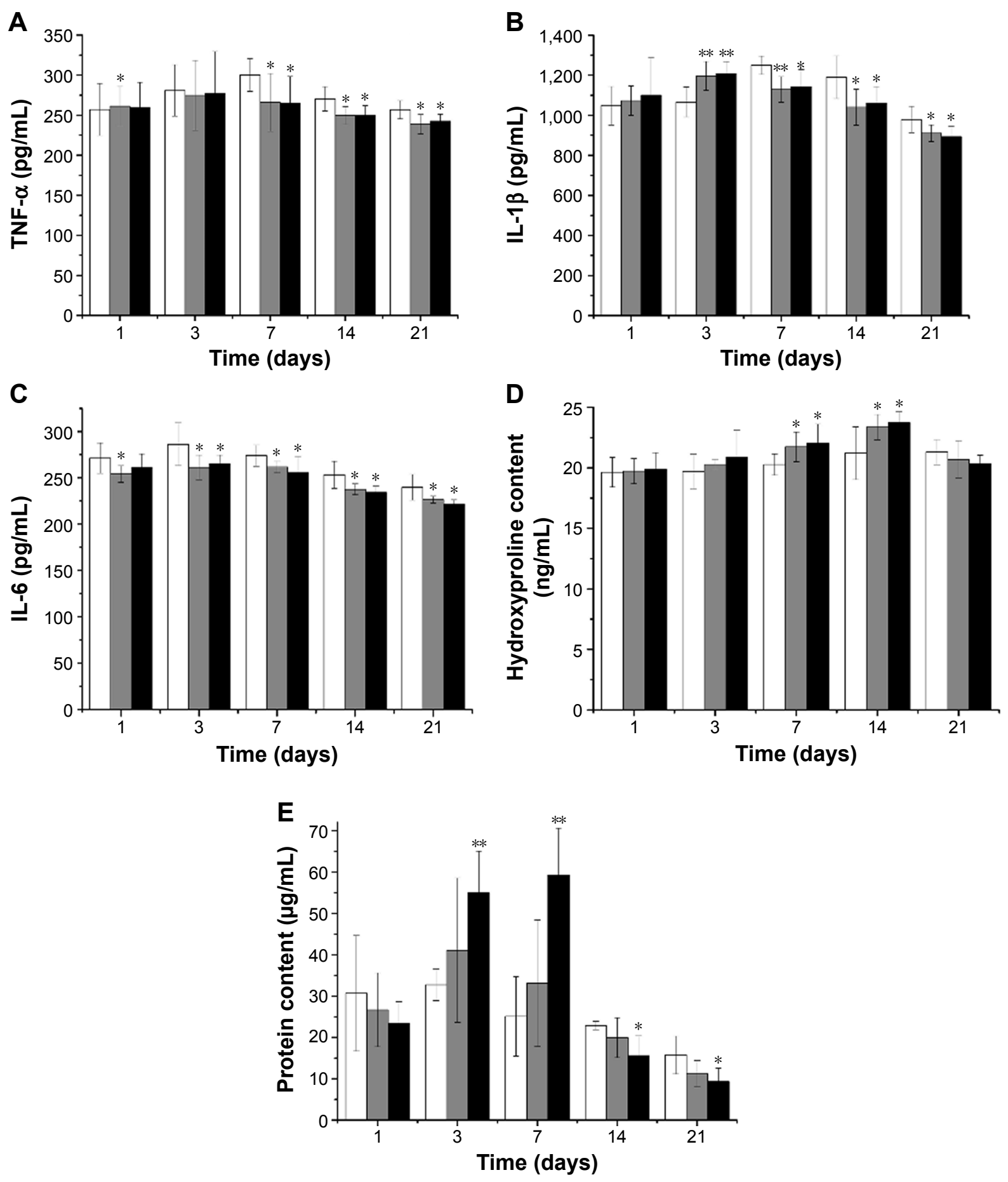

$\square$ Normal saline $\square$ Povidone-iodine $\mathbf{a g N P s}$

Figure 5 Levels of (A) TNF- $\alpha$, (B) IL-I $\beta$, (C) IL-6, (D) hydroxyproline, and (E) total protein were quantified from skin wounds.

Notes: Values are mean \pm SD for $n=6-8$. Statistical differences were found between samples labeled with $* P<0.05$ and $* * P<0.01$ compared to the control and normal saline.

Abbreviations: SD, standard deviation; IL, interleukin; TNF- $\alpha$, tumor necrosis factor alpha.

\section{Conclusion}

A simple one-pot green synthesis of stable AgNPs using the versatile strain $P$. spinulosum $\mathrm{OC}-11$ at room temperature was reported in this study. It was confirmed that the proteins produced by the endophytic fungus capped on the AgNPs and secured the nanoparticles with low aggregation, improved the inhibitory effect, and raised the identification to $S$. aureus, P. aeruginosa, and E. coli of the AgNPs. Furthermore, the AgNPs markedly accelerated the wound healing. This simple, nontoxic, environmentally benign, sustainable microbial 


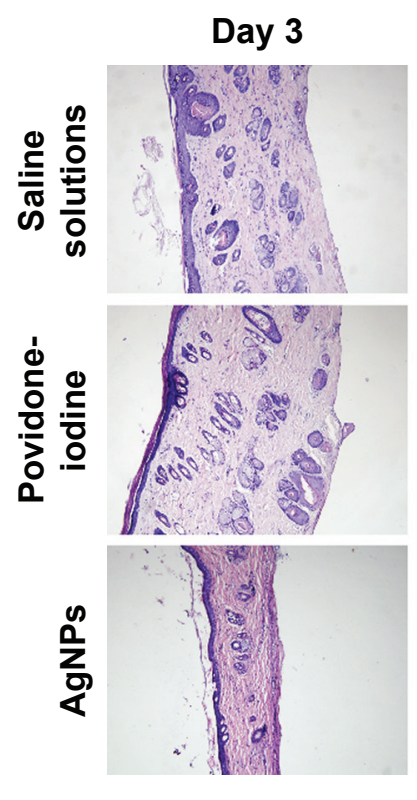

Day 7

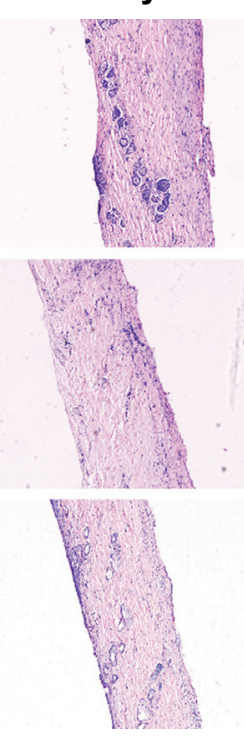

Day 14

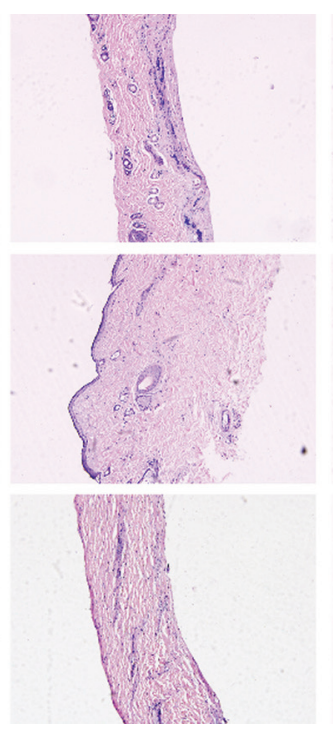

Day 21

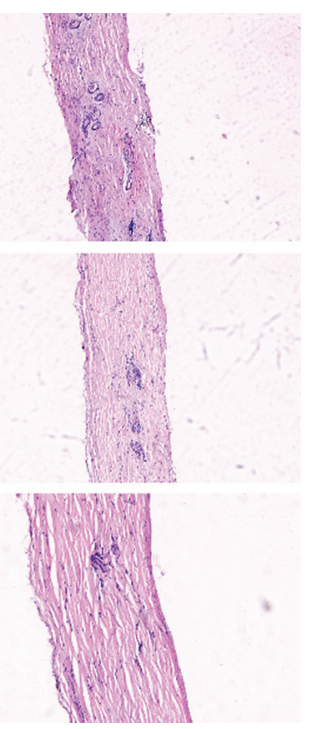

Figure $6 \mathrm{HE}$-stained sections of skin wound sample.

Note: Original magnification: $10 \times$.

Abbreviations: HE, hematoxylin and eosin; AgNPs, silver nanoparticles.

synthesis of AgNPs could be a competitive alternative to the conventional physical/chemical methods and will play an important role in biomedical applications in near future.

\section{Acknowledgments}

This work was supported by the National Natural Science Foundation of China (Grant Nos 81274097, 81573618), the Pearl River S\&T Nova Program of Guangzhou (Grant No 2013J2200059), and the Cultivation Foundation for Distinguished Young Teachers in Higher Education of Guangdong (Grant No Yq2013099).

\section{Disclosure}

The authors report no conflicts of interest in this work.

\section{References}

1. Wu J, Kamaly N, Shi J, et al. Development of multinuclear polymeric nanoparticles as robust protein nanocarriers. Angew Chem Int Ed Engl. 2014;53(34):8975-8979.

2. Yu Z, Xu Q, Dong C, et al. Self-assembling peptide nanofibrous hydrogel as a versatile drug delivery platform. Curr Pharm Des. 2015;21(29): 4342-4354.

3. Yu Z, Schmaltz RM, Bozeman TC, et al. Selective tumor cell targeting by the disaccharide moiety of bleomycin. J Am Chem Soc. 2013;135(8): 2883-2886.

4. Yu Z, Paul R, Bhattacharya C, et al. Structural features facilitating tumor cell targeting and internalization by bleomycin and its disaccharide. Biochemistry. 2015;54(19):3100-3109.

5. Malhotra A, Dolma K, Kaur N, et al. Biosynthesis of gold and silver nanoparticles using a novel marine strain of Stenotrophomonas. Bioresour Technol. 2013;142:727-731.

6. Saifullah SA, Ahmad M, Swami BL, et al. Green synthesis of silver nanoparticles using Azadirachta indica aqueous leaf extract. $J$ Radiat Res. 2016;9(1):1-7.
7. Otari SV, Patil RM, Ghosh SJ, et al. Intracellular synthesis of silver nanoparticle by actinobacteria and its antimicrobial activity. Spectrochim Acta A Mol Biomol Spectrosc. 2015;136:1175-1180.

8. Chi Z, Liu GL, Lu Y, et al. Bio-products produced by marine yeasts and their potential applications. Bioresour Technol. 2016;202:44-52.

9. Gade A, Gaikwad S, Duran N, et al. Green synthesis of silver nanoparticles by Phoma glomerata. Micron. 2014;59:52-59.

10. Korbekandi H, Chitsazi MR, Asghari G, et al. Green biosynthesis of silver nanoparticles using Quercus brantii (oak) leaves hydroalcoholic extract. Pharm Biol. 2015;5(6):807-812.

11. Beekman AM, Barrow RA. Stereochemical assignment of the fungal metabolites pestalotiopsones $\mathrm{D}$ and $\mathrm{E}$ through enantiopure synthesis. J Nat Prod. 2013;76(11):2054-2059.

12. Stierle A, Strobel G, Stierle D. Taxol and taxane production by Taxomyces andreanae, an endophytic fungus of Pacific yew. Science. 1993; 260(5105):214-216.

13. Li ZK. Study on the resources of rare and endangered medicinal plants in Guangdong. Q For By-Prod Spec China. 2001;56:61-62.

14. Yuan CQ, Wang NH, Lu Y. [Conservation of rare and endangered medicinal plants]. Zhongguo Zhong Yao Za Zhi. 1993;18(2):71-72. Chinese.

15. Kwan KH, Liu X, To MK, et al. Modulation of collagen alignment by silver nanoparticles results in better mechanical properties in wound healing. Nanomedicine. 2011;7(4):497-504.

16. Brause R, Moeltgen H, Kleinermanns K. Characterization of laser ablated and chemically reduced silver colloids in aqueous solution by UV-vis spectroscopy and STM/SEM microscopy. Appl Phys B. 2002; 75(6):711-716.

17. Rao CRK, Trivedi DC. Biphasic synthesis of fatty acids stabilized silver nanoparticles: role of experimental conditions on particle size. Mater Chem Phys. 2006;99(2-3):354-360.

18. Maliszewska I, Juraszek A, Bielska K. Green synthesis and characterization of silver nanoparticles using ascomycota fungi Penicillium nalgiovense AJ12. J Clust Sci. 2014;25(4):989-1004.

19. Nallathamby PD, Lee KJ, Xu XH. Design of stable and uniform single nanoparticle photonics for in vivo dynamics imaging of nanoenvironments of zebrafish embryonic fluids. ACS Nano. 2008;2(7):1371-1380.

20. Muthukrishnan S, Bhakya S, Senthil KT, et al. Biosynthesis, characterization and antibacterial effect of plant-mediated silver nanoparticles using Ceropegia thwaitesii - an endemic species. Ind Crops Prod. 2015;63:119-124. 
21. Vanaja M, Annadurai G. Coleus aromaticus leaf extract mediated synthesis of silver nanoparticles and its bactericidal activity. Appl Nanosci. 2013;3(3):217-223.

22. Shankar SS, Ahmad A, Parsricha R, et al. Bioreduction of chloroaurate ions by geranium leaves and its endophytic fungus yields gold nanoparticles of different shapes. J Mater Chem. 2003;13:1822-1826.

23. Mishra A, Kumari M, Pandey S, et al. Biocatalytic and antimicrobial activities of gold nanoparticles synthesized by Trichoderma sp. Bioresour Technol. 2014;166:235-242.

24. Cui F, Zan X, Li Y, et al. Purification and partial characterization of a novel anti-tumor glycoprotein from cultured mycelia of Grifola frondosa. Int J Biol Macromol. 2013;62:684-690.

25. Kretlow A, Wang Q, Kneipp J, et al. FTIR-microspectroscopy of prion-infected nervous tissue. Biochim Biophys Acta. 2006;1758(7): 948-959.

26. Scirè A, Baldassarre $\mathrm{M}$, Lupidi $\mathrm{G}$, et al. Importance of $\mathrm{pH}$ and disulfide bridges on the structural and binding properties of human $\alpha 1$-acid glycoprotein. Biochimie. 2011;93(9):1529-1536.

27. Zhou RM, Shen YJ. Study on secondary structures of a protein by infrared spectra. J East China Univ Sci Technol. 1997;23(4):422-425.

28. Cui FJ, Li YH, Zan XY, et al. Purification and partial characterization of a novel hemagglutinating glycoprotein from the cultured mycelia of Hericium erinaceus. Process Biochem. 2014;49(8):1362-1369.

29. Nie SP, Xie MY, Fu ZH, et al. Study on the purification and chemical compositions of tea glycoprotein. Carbohyd Polym. 2008;71(4): 626-633.
30. Bawaskar M, Gaikwad S, Ingle A, et al. A new report on mycosynthesis of silver nanoparticles by Fusarium culmorum. Curr Nanosci. 2010;6(4): 376-380.

31. Gajbhiye M, Kesharwani J, Ingle A, et al. Fungus-mediated synthesis of silver nanoparticles and their activity against pathogenic fungi in combination with fluconazole. Nanomedicine. 2009;5(4):382-386.

32. Sanghi R, Verma P. Biomimetic synthesis and characterization of protein capped silver nanoparticles. Bioresour Technol. 2009;100:501-504.

33. Huang J, Li Q, Sun D, et al. Biosynthesis of silver and gold nanoparticles by novel sundried Cinnamomum camphora leaf. Nanotechnology. 2007; $18: 105104$.

34. Mohammadi B, Salouti M. Extracellular biosynthesis of silver nanoparticles by Penicillium chrysogenum and Penicillium expansum. Synth React Inorg Met Org Chem. 2015;45(6):844-847.

35. Burnouf T, Chou ML, Wu YW, et al. Antimicrobial activity of platelet (PLT)-poor plasma, PLT-rich plasma, PLT gel, and solvent/detergenttreated PLT lysate biomaterials against wound bacteria. Transfusion. 2013;53(1):138-146.

36. Percival SL, Hill KE, Williams DW, et al. A review of the scientific evidence for biofilms in wounds. Wound Repair Regen. 2012;20(5): 647-657.

37. Samy RP, Kandasamy M, Gopalakrishnakone P, et al. Wound healing activity and mechanisms of action of an antibacterial protein from the venom of the eastern diamondback rattlesnake (Crotalus adamanteus). PLoS One. 2014;9(2):e80199.
International Journal of Nanomedicine

\section{Publish your work in this journal}

The International Journal of Nanomedicine is an international, peerreviewed journal focusing on the application of nanotechnology in diagnostics, therapeutics, and drug delivery systems throughout the biomedical field. This journal is indexed on PubMed Central, MedLine, CAS, SciSearch $®$, Current Contents $\AA /$ Clinical Medicine,

\section{Dovepress}

Journal Citation Reports/Science Edition, EMBase, Scopus and the Elsevier Bibliographic databases. The manuscript management system is completely online and includes a very quick and fair peer-review system, which is all easy to use. Visit http://www.dovepress.com/ testimonials.php to read real quotes from published authors. 